\title{
The prevalence of maternal hypothyroidism in first trimester screening from 11 to 14 weeks of gestation
}

\author{
Tomas Salek ${ }^{\mathrm{a}, \mathrm{b}}$, Ishraq Dhaifalah ${ }^{\mathrm{b}, \mathrm{c}, \mathrm{d}}$, Dagmar Langova ${ }^{\mathrm{e}}$, Jana Havalova
}

\begin{abstract}
Aim. The aim of this study was to determine the prevalence of maternal hypothyroidism in the first trimester from 11 to 14 weeks of gestation according to the American Thyroid Association (ATA) guidelines from 2017 and to compare the rates for singleton and twin pregnancies.

Methods. A total of 4965 consecutive Caucasian singleton pregnancies and 109 Caucasian twin pregnancies were included in the investigation. Patients with a history of thyroid gland disorder were excluded. Subclinical maternal hypothyroidism was defined as a thyroid stimulating hormone (TSH) concentration above the $97.5^{\text {th }}$ percentile and free thyroxine (fT4) within the range of a reference population of women at 11-14 weeks of gestation. Overt maternal hypothyroidism was defined as a TSH concentration above the $97.5^{\text {th }}$ percentile and an fT4 below the $2.5^{\text {th }}$ percentile of the reference population.TSH, fT4, and anti thyroid peroxidase antibody (TPOAb) were measured by immunochemiluminescent assays on an 16200 Abbott Architect analyzer.

Results. The prevalence of hypothyroidism for twin pregnancies was no higher than that for singleton pregnancies; $6.42 \%$ (7/109) vs. 5.32\% (264/4965), respectively; $P=0.61$. All twin pregnancies were subclinical. Singleton hypothyroid pregnancies included $4.91 \%$ (244 cases) of subclinical and $0.41 \%$ (20 cases) of overt hypothyroidism. The prevalence of TPOAb positive hypothyroid women for twin pregnancies and singleton pregnancies was 71\% (5/7) vs. 52\% (137/264 cases), respectively but the differences were not statistically significant; $P=0.31$.

Conclusion. Each first trimester screening center should establish its TSH and fT4 reference ranges. Our center had higher upper reference limits of TSH than that of the universally fixed limit of $2.5 \mathrm{mU} / \mathrm{L}$, which led to a lower measured prevalence of maternal hypothyroidism. A large number of hypothyroid women were TPOAb positive.
\end{abstract}

Key words: hypothyroidism, pregnancy, thyroid disease, immunoassay, gestation

Received: June 2, 2018; Revised: September 19, 2018; Accepted: October 2, 2018; Available online: November 6, 2018 https://doi.org/10.5507/bp.2018.063

(c) 2019 The Authors. This is an open access article licensed under the Creative Commons Attribution License

(https://creativecommons.org/licenses/by/4.0/).

${ }^{a}$ Department of Clinical Biochemistry and Pharmacology, Tomas Bata Hospital in Zlin a. S., Havlickovo nabrezi 600, 76275 Zlin, Czech Republic

${ }^{b}$ Department of Biomedical Sciences, Faculty of Medicine, University of Ostrava, Syllabova 19, 70300 Ostrava - Zabreh, Czech Republic 'Department of Obstetrics and Gynecology, Tomas Bata Hospital in Zlin a. s., Havlickovo nabrezi 600, 76275 Zlin, Czech Republic ${ }^{d}$ FETMED (Fetmed Fetal Medicine Center and Genetics), Olomouc and Ostrava, Czech Republic eInternal Medicine Clinic, Tomas Bata Hospital in Zlin a. S., Havlickovo nabrezi 600, 76275 Zlin, Czech Republic Corresponding author: Tomas Salek, e-mail: tsalek@seznam.cz

\section{INTRODUCTION}

Optimal maternal thyroid function is essential for fetal growth and development as the fetal thyroid gland only reaches maturity by week $11-12$, close to the end of the first trimester, and begins to secrete thyroid hormones by about week 16 (ref. $^{1}$ ).

Maternal thyroid dysfunction is associated with increased risk of various adverse maternal and child outcomes, including miscarriage, intrauterine growth retardation, hypertensive disorders, preterm delivery, and a decreased child IQ $\left(\right.$ ref. $^{2}$ ).

Hypothyroidism in pregnant women can adversely affect their children's subsequent performance on neuropsychological tests ${ }^{3}$.

The physiological regulation of thyroid hormone secretion is changed in pregnancy. Human chorionic gonadotropin (HCG) produced by the placenta directly stimulates the production of thyroxine (T4) and triiodothyronine (T3) by the maternal thyroid gland. Negative feedback regulation by free thyroid hormones decreases the production of TSH by the anterior pituitary gland in pregnancy to values lower than those in the general population ${ }^{4}$.

Increased iodine supply is required for the adequate synthesis of T3 and T4 in pregnancy. Universal salt iodization is the first-line strategy for the elimination of severe iodine deficiency and iodine supplementation may be further recommended for pregnant women ${ }^{5}$.

Maternal hypothyroidism is a major public health problem and meets the general criteria for screening. Universal or selected screening programs may be discussed $^{6}$.

The definition of overt and subclinical hypothyroidism is based on TSH and fT4 laboratory test results. Interpretation of any laboratory test depends on cut-off 
values or reference ranges. Current guidelines define reference ranges as $2.5^{\text {th }}$ and $97.5^{\text {th }}$ percentiles of TSH and fT4 concentrations of a reference population in serum. For decision making in pregnancy, percentile-based reference ranges are preferred over the universally fixed limit of 2.5 $\mathrm{mU} / \mathrm{L}$. Subclinical maternal hypothyroidism is defined as TSH plasma concentration above $97.5^{\text {th }}$ percentile of a reference population with or without positivity of TPOAb and fT4 within reference ranges. Overt hypothyroidism is a combination of TSH above the $97.5^{\text {th }}$ percentile and fT4 below $2.5^{\text {th }}$ percentile of the reference population ${ }^{7}$.

The cut off point determines how many subjects will be considered as having the disease. The prevalence of maternal hypothyroidism is not well established. This motivated us to determine the prevalence of maternal hypothyroidism and compare the rates for singleton and twin pregnancies in our fetal medicine center using current ATA guidelines.

\section{MATERIALS AND METHODS}

\section{Subjects}

A retrospective observational study design was used. Data were analyzed from January 2010 to November 2017. A total of 4965 singleton and 109 twin consecutive Caucasian pregnant women who underwent simultaneously both prenatal first trimester Down's syndrome and thyroid function screening with results for TSH, fT4 and TPOAb included in the study. Women with a medical history of thyroid disease were excluded from the screening. Those positive for TPOAb were excluded for the determination of the reference limits of fT4 (678 singleton and 12 twin pregnancies).

The median, interquartile range (IQR) of age for singleton pregnancies was 30 years $(26-33)$ and 31 years (27-34) for twin pregnancies.

Adequate iodine supplementation was assumed because of the universal availability of iodized salt in Czech Republic from 1947 ( ref. $^{8}$ ).

The study was approved by the Tomas Bata hospital Ethics committee in Zlín, Czech Republic and performed according to Declaration of Helsinki.

\section{Methods}

TSH, fT4, and TPOAb were measured by immunochemiluminescent assays on ci 16200 Abbott Architect analyzer.
Institutional assay specific $2.5^{\text {th }}$ and $97.5^{\text {th }}$ percentiles of TSH and fT4 of reference population of women pregnant from 11 to 14 weeks of gestation were used for decision making. Women with history of thyroid disease and positivity of TPOAb were excluded for establishment of reference intervals. The positivity of TPOAb was defined as a concentration of $5.6 \mathrm{kU} / \mathrm{L}$ and higher according to manufacturer recommendation.

The reference ranges of TSH in singleton and twin pregnancies followed in our center were previously published ${ }^{9}$.

Reference intervals of TSH and fT4 for both singleton and twin pregnancies are shown in Table 1.

Subclinical hypothyroidism was defined as concentration of TSH elevated above $97.5^{\text {th }}$ percentile and concentration of fT4 within reference ranges of our reference population.

Overt hypothyroidism was defined as elevation of TSH concentration above $97.5^{\text {th }}$ percentile and decline of fT4 below $2,5^{\text {th }}$ percentile of our reference population.

\section{Statistical analysis}

MedCalc statistical software version 17.4 (MedCalc Software bvba, Ostend, Belgium) was used for data analysis. D'Agostino-Pearson test was employed for normal distribution testing. The normal distribution was rejected for all parameters. The nonparametric percentile method was used for calculation of $2.5^{\text {th }}$ and $97.5^{\text {th }}$ percentile of TSH and fT4. Mann-Whitney test for independent samples was used for comparison of medians of fT4.

Two sided chi-squared test was used for comparison of proportions.

\section{RESULTS}

The median (IQR) of gestational age for singleton pregnancies was 12 weeks +5 days $(12+2-13+0)$ and for twin pregnancies 12 weeks +5 days $(12+2-13+1)$.

The prevalence of hypothyroidism for twin pregnancies was no higher than that for singleton pregnancies; $6.42 \%$ ( 7 cases out of 109 ) vs. $5.32 \%$ (264 cases out of 4965), respectively; $P=0.61$. All twin pregnancies were subclinical. Singleton hypothyroid pregnancies included $4.91 \%$ ( 244 cases) of subclinical and $0.41 \%$ ( 20 cases) of overt cases.

The prevalence of TPOAb positive hypothyroid women for twin pregnancies and singleton pregnancies was

Table 1. Reference ranges of TSH and fT4 for singleton and twin pregnancies from 11 to $13+6$ weeks of gestation.

\begin{tabular}{lcc}
\hline & Lower Reference Limit & Upper reference limit \\
\hline TSH Singleton pregnancy $(\mathrm{n}=10592)$ & $0.16 \mathrm{mU} / \mathrm{L}$ & $3.43 \mathrm{mU} / \mathrm{L}$ \\
TSH Twin pregnancy $(\mathrm{n}=201)$ & $0.02 \mathrm{mU} / \mathrm{L}$ & $2.95 \mathrm{mU} / \mathrm{L}$ \\
fT4 Singleton pregnancy $(\mathrm{n}=4287)$ & $11.8 \mathrm{pmol} / \mathrm{L}$ & $18.4 \mathrm{pmol} / \mathrm{L}$ \\
fT4 Twin pregnancy $(\mathrm{n}=97)$ & $12.2 \mathrm{pmol} / \mathrm{L}$ & $23.2 \mathrm{pmol} / \mathrm{L}$ \\
\hline
\end{tabular}

TSH: Thyroid stimulating hormone fT4: free thyroxine 
$71 \%(5 / 7)$ vs. $52 \%(137 / 264$ cases $)$, respectively but the differences were not statistically significant; $P=0.31$.

The median fT4 concentrations for twin pregnancies was no higher than that for singleton pregnancies 14.6 $\mathrm{pmol} / \mathrm{L}$ vs. $14.6 \mathrm{pmol} / \mathrm{L}$, respectively; $P=0.13$.

\section{DISCUSSION}

The prevalence of maternal hypothyroidism in first trimester screening from 11 to 14 weeks of gestation was determined.

The ATA guidelines from 2011 also suggested in its recommendation number 2 as a universal cut-off limit for decision making: if trimester-specific reference ranges for TSH are not available in the laboratory, the following reference ranges are recommended: first trimester, 0.1-2.5 $\mathrm{mIU} / \mathrm{L}$; second trimester, 0.2-3.0 mIU/L; third trimester, 0.3-3.0 mIU/L (ref. ${ }^{10}$ ). Carty et al. reported that using a TSH cut-off of $2.5 \mathrm{mU} / \mathrm{L}$ in keeping with European and US guidelines means that over $12 \%$ of women in this cohort would be classified as having subclinical hypothyroidism ${ }^{11}$. The universal limit of $2.5 \mathrm{mU} / \mathrm{L}$ would lead to much higher prevalence of maternal hypothyroidism also in our cohort.

Medici et al. in a review found that $90 \%$ of all upper limits of TSH are higher than the recommended fixed TSH cutoff concentrations of $2.5 \mathrm{mU} / \mathrm{L}$ for first trimester $^{2}$. It is consistent with our results.

Springer et al. established reference ranges for seven analytical platforms of measurement and all of them had their upper reference limit defined as $97.5^{\text {th }}$ percentile higher than the fixed limit of $2.5 \mathrm{mU} / \mathrm{L}$ (ref. ${ }^{12}$ ). Abbott Architect platform was also included with similar results of upper reference limit, which would lead to similar subclinical hypothyroidism prevalence.

Castillo et al. also used the $97.5^{\text {th }}$ percentile as the upper reference limit of TSH normal values and found their prevalence of subclinical hypothyroidism of $5 \%$ (ref. ${ }^{13}$ ). It supports our results.

Casey et al. showed that the prevalence of maternal subclinical hypothyroidism exceeded $6 \%$ using $97.5^{\text {th }}$ percentile of TSH upper limit of reference population ${ }^{14}$.

Lin et al. reported an association between $\mathrm{TSH}$ and positivity for TPOAb in a cohort of pregnant women in early pregnancy ${ }^{15}$. It supports our finding of much higher prevalence of TPOAb positivity in hypothyroid women compared to euthyroid ones.

Ashoor et al. demonstrated the same serum concentrations of fT4 in both singleton and twin pregnancies ${ }^{16}$. Our results confirm this.

The limitation of this study is that we did not measure anti thyreoglobulin antibodies in serum or iodine in urine.

\section{CONCLUSION}

In summary, each screening center should establish its TSH and fT4 reference ranges. Our center has a higher upper reference limit of TSH than that of universally fixed limit of $2.5 \mathrm{mU} / \mathrm{L}$, which led to a lower measured prevalence of maternal hypothyroidism. Both the prevalence of hypothyroidism and positivity of TPOAb were the same for both singleton and twin pregnancies.

Author contributions: TS: data interpretation, drafting the article, final approval, agreement to be accountable for all aspects of the work; ID: acquisition of data, revising the article, final approval, agreement to be accountable for all aspects of the work; DL: data interpretation, revising the article, final approval, agreement to be accountable for all aspects of the work; JH: acquisition of data, revising the article, final approval, agreement to be accountable for all aspects of the work.

Conflict of interest statement: None declared.

\section{REFERENCES}

1. Patel J, Landers K, Li H, Mortimer RH, Richard K. Thyroid hormones and fetal neurological development. J Endocrinol 2011;209(1):1-8.

2. Medici M, Korevaar TI, Visser WE, Visser TJ, Peeters RP. Thyroid function in pregnancy: what is normal? Clin Chem 2015;61(5):704-13.

3. Haddow JE, Palomaki GE, Allan WC, Williams JR, Knight GJ, Gagnon J. Maternal thyroid deficiency during pregnancy and subsequent neuropsychological development of the child. N Engl J Med 1999;341(8):549-55.

4. Alemu A, Terefe B, Abebe M, Biadgo B. Thyroid hormone dysfunction during pregnancy: A review. Int J Reprod Biomed 2016;14(11):67786.

5. Pearce EN, Lazarus JH, Moreno-Reyes R, Zimmermann MB. Consequences of iodine deficiency and excess in pregnant women: an overview of current knowns and unknowns12. Am J Clin Nutr 2016;104(Suppl 3):918S-23S.

6. Springer D, Jiskra J, Limanova Z, Zima T, Potlukova E. Thyroid in pregnancy: From physiology to screening. Crit Rev Clin Lab Sci 2017;54(2):102-16.

7. Alexander EK, Pearce EN, Brent GA, Brown RS, Chen H, Dosiou C, Grobman WA, Laurberg P, Lazarus JH, Mandel SJ, Peeters RP, Sullivan S. 2017 Guidelines of the American Thyroid Association for the Diagnosis and Management of Thyroid Disease During Pregnancy and the Postpartum. Thyroid 2017;27(3):315-89.

8. Zamrazil V, Bilek R, Cerovska J, Delange F. The elimination of iodine deficiency in the Czech Republic: the steps toward success. Thyroid 2004;14(1):49-56.

9. ŠálekT, Dhaifalah I, Langova D, Havalová J. Maternal thyroid-stimulating hormone reference ranges for first trimester screening from 11 to 14 weeks of gestation. J Clin Lab Anal 2018 Feb 3. [Epub ahead of print] doi:10.1002/jcla.22405.

10. Stagnaro-Green A, Abalovich M, Alexander E, Azizi F, Mestman J, Negro R, Nixon A, Pearce EN, Soldin OP, Sullivan S, Wiersinga W; American Thyroid Association Taskforce on Thyroid Disease During Pregnancy and Postpartum. Guidelines of the American Thyroid Association for the diagnosis and management of thyroid disease during pregnancy and postpartum. Thyroid 2011;21(10):1081-125.

11. Carty DM, Doogan F, Welsh P, Dominiczak AF, Delles C. Thyroid stimulating hormone $(\mathrm{TSH}) \geq 2.5 \mathrm{mU} / \mathrm{l}$ in early pregnancy: Prevalence and subsequent outcomes. Eur J Obstet Gynecol Reprod Biol 2017;210:366-9.

12. Springer D, Bartos V, Zima T. Reference intervals for thyroid markers in early pregnancy determined by 7 different analytical systems. Scand J Clin Lab Invest 2014;74(2):95-101.

13. Castillo Lara M, Vilar Sánchez Á, Cañavate Solano C, Soto Pazos E, Iglesias Álvarez M, González Macías C, Ayala Ortega C, Moreno Corral LJ, Fernández Alba JJ. Hypothyroidism screening during first trimester of pregnancy. BMC Pregnancy Childbirth 2017;17(1):438.

14. Casey BM, Thom EA, Peaceman AM, Varner MW, Sorokin Y, Hirtz DG, Reddy UM, Wapner RJ, Thorp JM Jr, Saade G, Tita AT, Rouse DJ, Sibai 
B, lams JD, Mercer BM, Tolosa J, Caritis SN, VanDorsten JP; Eunice Kennedy Shriver National Institute of Child Health and Human Development Maternal-Fetal Medicine Units Network. Treatment of Subclinical Hypothyroidism or Hypothyroxinemia in Pregnancy. N Engl J Med 2017;376(9):815-25.
15. Lin L, Zhang XL, Long Y. Analysis of thyroid peroxidase antibody in early pregnancy. Genet Mol Res 2014;13(3):5107-14.

16. Ashoor G, Muto O, Poon LCY, Muhaisen M, Nicolaides KH. Maternal thyroid function at gestational weeks 11-13 in twin pregnancies. Thyroid 2013;23(9):1165-71. 